\title{
Preparation and Characterization of Nanozeolite NaA from Rice Husk at Room Temperature without Organic Additives
}

\author{
Zahra Ghasemi and Habibollah Younesi \\ Department of Environmental Science, Faculty of Natural Resources and Marine Sciences, Tarbiat Modares University, \\ P.O. Box 46414-356, Noor, Iran \\ Correspondence should be addressed to Habibollah Younesi, hunesi@modares.ac.ir
}

Received 21 April 2010; Revised 23 August 2010; Accepted 21 November 2010

Academic Editor: Quanqin Dai

Copyright ( $\odot 2011$ Z. Ghasemi and H. Younesi. This is an open access article distributed under the Creative Commons Attribution License, which permits unrestricted use, distribution, and reproduction in any medium, provided the original work is properly cited.

\begin{abstract}
Nanozeolite NaA was synthesized by the hydrothermal method with silica extracted from rice husk as silica source. Amorphous silica with $87.988 \mathrm{wt} \% \mathrm{SiO}_{2}$ was extracted from rice husk ash by a suitable alkali solution. The effect of the crystallization time and the ratio of $\mathrm{Na}_{2} \mathrm{O} / \mathrm{SiO}_{2}$ on the properties of the final product was investigated. The synthesized nanozeolite was characterized by X-ray diffraction (XRD), scanning electron microscope (SEM), transmission electron microscopy (TEM), energy-dispersive X-ray (EDX) techniques, and Brunauer-Emmett-Teller (BET) method. Results revealed that the crystallization time and alkalinity have significant effects on the structural properties of nanozeolite. Nanocrystals NaA with crystal sizes ranging from 50 to $120 \mathrm{~nm}$ were synthesized at room temperature with 3 days aging, without adding any organic additives.
\end{abstract}

\section{Introduction}

Zeolites are a series of microporous crystals with intricate pores and channels. They have widely been used as catalysts, adsorbents, and ion exchangers $[1,2]$. During the past decade, decreasing of the crystallization time at moderate temperature in the preparation of zeolite-type materials has successfully been achieved $[3,4]$. Indeed, natural zeolites are often formed at low temperature in closed alkaline and saline lake systems [5]. The crystallization at a moderate temperature has a pronounced effect on the ultimate zeolite crystal size. In addition, the preparation of mesoporous materials at moderate temperature has economic and environmental benefits and can be used for fundamental studies of chemical reactions during the crystallization period [6].

Various types of nanometer-sized zeolites, including $\mathrm{NaA}$, faujasite-X and -Y, ZSM-5, and silicalite-1, have been synthesized by hydrothermal procedures using clear aluminosilicate solutions in the presence of organic templates [712]. Recently, Pan et al. reported the synthesis of zeolite A nanocrystals in a two-phase liquid segmented microfluidic reactor using a manipulated organic-template-free system
[13]. However, the application of the organic-templates has several disadvantages. They are nonrecyclable, costly, and require calcinations which results in the production pollution problems $[12,14]$.

Rice husk has been used as an active silica source for the synthesis of A [15], beta [16], and ZSM-5 zeolites [17]. As an alternative to the pure chemical sources used previously, rice husk is a practical silica source, because it is cheap, less selective, and highly active [18].

Initially, rice husk is burned completely to produce ash, converting the organic siliceous material of the husk into white ash, silica, which is considered an unreactive and useless mineral [19], but by a suitable alkali solution, amorphous silica, which is highly reactive for some zeolites synthesis, can be extracted from the rice husk ash, thus showing rice husk to be an excellent source of high-grade silica [2022].

The aims of this paper were to extract active amorphous silica from rice husk and to synthesize crystalline zeolite $\mathrm{NaA}$ in nanometer size using extracted silica from rice husk at room temperature without adding any organic additives. In order to decrease the cost of the synthesis and reduce 
the crystallization time, special attention was paid to the alkalinity and the $\mathrm{Na}_{2} \mathrm{O} / \mathrm{SiO}_{2}$ ratio of initial system which control the kinetics of the zeolite growth.

\section{Experimental Methods}

2.1. Silica Extraction from Rice Husk. Rice husks were sieved to eliminate clay particles. They were washed with distilled water, filtered, and then soaked in $\mathrm{HCl}$ (Merck, 37\%) solution $(1 \mathrm{M})$ for $8 \mathrm{~h}$. After leaching with $\mathrm{HCl}$, they were washed well with distilled water, dried in air, and calcined at $700^{\circ} \mathrm{C}$ for $6 \mathrm{~h}$ with a constant heating rate $10^{\circ} \mathrm{C} / \mathrm{min}$. The obtained rice husk ash was dissolved in $\mathrm{NaOH}(2 \mathrm{M}$, Merck, 98\%, 2 M) solution followed by refluxing for $12 \mathrm{~h}$. For complete precipitation, concentrated $\mathrm{HCl}$ was added to the dissolved rice husk ash. Above-mentioned precipitated solution was filtered, washed with distilled water till free from chloride ions, and finally dried in an oven at $110^{\circ} \mathrm{C}$ overnight.

2.2. Nanozeolite NaA Preparation. The nanometer-sized NaA zeolite was synthesized by hydrothermal crystallization [23]. Colloidal crystals of zeolite A were formed in a clear homogenized solution with the following molar composition: $\mathrm{Na}_{2} \mathrm{O}$ : $0.55 \mathrm{Al}_{2} \mathrm{O}_{3}: 1 \mathrm{SiO}_{2}: 150 \mathrm{H}_{2} \mathrm{O}$ in which $x=0.9,6$, and 9 to determine the optimal $\mathrm{Na}_{2} \mathrm{O} / \mathrm{SiO}_{2}$ ratio for synthesis of nanozeolite $\mathrm{NaA}$. The gel composition of $\mathrm{NaA}$ nanozeolite was calculated based on the results of the XRF analysis of extracted silica source. Typically, $7.79 \mathrm{~g}$ of $\mathrm{NaOH}$ was dissolved in $2.77 \mathrm{~mol}$ of $\mathrm{H}_{2} \mathrm{O}$ and then divided into two equal portions. For the synthesis of NaA zeolite, $1.26 \mathrm{~g}$ of silica source, extracted from rice husk ash, was completely dissolved in one portion of the $\mathrm{NaOH}$ solution. An aluminate solution was prepared by mixing $2.04 \mathrm{~g}$ of $\mathrm{NaAlO}_{2}$ (Merck) with another portion of the $\mathrm{NaOH}$ solution. After achieving clearness of the solutions, the silicate solution was slowly poured into the aluminate solution with vigorous stirring, which resulted in a clear homogenous solution. The resultant mixture was stored in an oil bath at room temperature $(T=$ $25 \pm 2^{\circ} \mathrm{C}$ ), in a sealed polypropylene bottle under stirrer (250 rpm) conditions for different crystallization periods (1, 2 , and 3 days). The solid product obtained in the synthesis was separated by centrifugation $(17000 \mathrm{rpm}, 30 \mathrm{~min})$ then washed several times with distilled water until the $\mathrm{pH}$ value dropped to 8.5 . The products were dried in an oven at $110^{\circ} \mathrm{C}$ overnight.

2.3. Characterization. Proximate analysis of rice husk was measured by ASTM method [24]. The chemical composition of extracted silica powder from rice husk was determined by X-ray fluorescence (XRF, Philips PW2404 Spectrometer). The powder X-ray diffraction (XRD) patterns of NaA zeolite and extracted silica were measured by a Philips diffractometer (X'Pert, PW1800). The patterns were run with Ni-filtered copper radiation $(\mathrm{K} \alpha=1.5404 \AA$ ) $)$ at $30 \mathrm{kV}$ voltage and 10 $\mathrm{mA}$ current with scanning speed of $2 \mathrm{~h}=2.5^{\circ} / \mathrm{min}$.

The morphology and size of the prepared materials were determined using a scanning electron microscope (SEM,

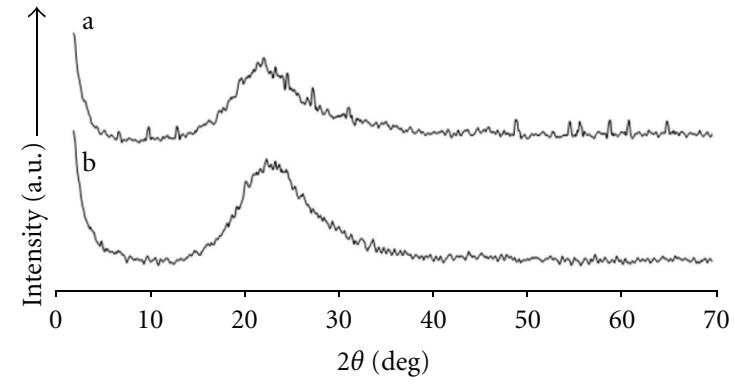

FIGURE 1: The XRD analysis of (a) rice husk ash and (b) extracted silica powder.

Philips XL30, operated at $30 \mathrm{KV}$ ). Prior to placing into the microscope, the prepared materials of the NaA zeolite were sprinkled uniformly over an adhesive tape and sputter coated with a thin layer of gold, and an electron acceleration voltage of $20 \mathrm{kV}$ was applied.

Scanning transmission electron microscopy (STEM, Philips CM200 at $200 \mathrm{kV}$ ) coupled with selected area electron diffraction (SAED) was used to characterize synthesized zeolite crystals.

The Si/Al ratio of the final nanosized $\mathrm{NaA}$ was determined by energy-dispersive X-ray (EDX) spectrophotometer of above-mentioned SEM and XRF techniques.

Nitrogen adsorption/desorption isotherms were measured at $77^{\circ} \mathrm{K}$ using a conventional volumetric apparatus. The specific surface area was obtained using the BET (BrunauerEmmett-Teller) method. The micropore volume and the external surface area were obtained from the $t$-plot method.

The loss of ignition (LOI) test was carried out following the SIRIM procedure (ISO 3262-1975). About $1 \mathrm{~g}$ of dried sample of the extracted silica was placed in a platinum crucible and ignited in the muffled furnace at $1000^{\circ} \mathrm{C}$ for 30 minutes to achieve a constant mass, followed by cooling in a desiccator. The loss of ignition, as a percentage by mass, is given by the formula:

$$
\text { LOI, } \%=\frac{M_{0}-M_{1}}{M_{0}} \times 100,
$$

where $M_{0}$ is the mass of the sample and $M_{1}$ is the mass of the sample after ignition.

\section{Results and Discussion}

3.1. Characterization of Rice Husk Ash and Extracted Silica. Proximate analysis showed the presence of $9.26 \%$ moisture, $71.62 \%$ volatile matter, $18.63 \%$, ash, and $0.49 \%$ fixed carbon in RHA. The XRD spectra of the ash and extracted silica are shown in Figure 1.

Rice husk was burned completely to produce carbonfree white ash. The silica content of calcined rice husk showed a weight loss of more than $70 \%$. The organic matter of rice husk was removed by heating treatments at high temperatures, but this led to the crystallization of the ash [25]. The XRD analysis of ash (Figure 1(a)), which was heat treated at $700^{\circ} \mathrm{C}$ for $6 \mathrm{~h}$, showed the crystalline phase 
TABLE 1: The XRF analysis results of ash and extracted silica powder.

\begin{tabular}{lcc}
\hline Composition & Ash (wt \%) & Extracted silica powder (wt \%) \\
\hline $\mathrm{Fe}_{2} \mathrm{O}_{3}$ & 0.104 & 0.047 \\
$\mathrm{CaO}$ & 0.539 & 0.085 \\
$\mathrm{~K}_{2} \mathrm{O}$ & 0.103 & 0.121 \\
$\mathrm{SiO}_{2}$ & 95.913 & 87.988 \\
$\mathrm{Al}_{2} \mathrm{O}_{3}$ & 0.192 & 0.477 \\
$\mathrm{MgO}$ & 0.24 & 0.077 \\
$\mathrm{Na}_{2} \mathrm{O}$ & - & 0.566 \\
$\mathrm{P}_{2} \mathrm{O}_{5}$ & 0.302 & - \\
$\mathrm{SO}_{3}$ & 0.044 & - \\
$\mathrm{LOI}$ & 2.562 & 10.64 \\
\hline
\end{tabular}

of the supplied rice husk ash in the form of cristobalite, tridymite, and quartz. The existence of peaks at $2 \theta=21.9^{\circ}$, $28.5^{\circ}, 31.5^{\circ}$, and $36.3^{\circ}$ corresponds to the cristobalite [26]. The main characteristic signals at $20.6^{\circ}, 23.3^{\circ}, 27.5^{\circ}, 30.2^{\circ}$, and $36.1^{\circ}$ [16] and at $20.88^{\circ}, 26.66^{\circ}, 50.18^{\circ}$, and $60^{\circ}$ [27] were assigned to tridymite and quartz, respectively. The crystallization of the contained silica of the rice husk ash occurs when the husk burning conditions are uncontrolled [28]. The crystalline form of ash in this study is attributed to heating at high temperature rather than to uncontrolled burning conditions, because the burning was controlled at the rate of $10^{\circ} \mathrm{C} / \mathrm{min}$.

The silica powder was extracted from obtained ash by a $\mathrm{NaOH}$ solution. According to the XRD analysis (Figure 1(b)), the extracted silica powder was amorphous. The broad peak at $2 \theta$ angle of $22^{\circ}$ confirmed the amorphous nature of the silica in this study [29]. Similar properties of rice husk have been reported by Kalapathy et al. [29]. This amorphous form is an advantage towards the preparation of silicon-based materials like zeolites, because the silica is rendered active in its amorphous form [30].

The results of the XRF analysis of rice husk ash and extracted silica powder are listed in Table 1. As the table shows, the weight percent of impurities including $\mathrm{Fe}_{2} \mathrm{O}_{3}$, $\mathrm{CaO}, \mathrm{MgO}, \mathrm{P}_{2} \mathrm{O}_{5}$, and $\mathrm{SO}_{3}$ was reduced in extracted silica powder in comparison with rice husk ash, but the weight percent of $\mathrm{K}_{2} \mathrm{O}, \mathrm{Al}_{2} \mathrm{O}_{3}$, and $\mathrm{Na}_{2} \mathrm{O}$ was increased and their amount was calculated and applied for synthesis of the nanozeolite.

The LOI was determined by heating certain quantities of rice husk ash and extracted silica samples in the muffled furnace at $1000^{\circ} \mathrm{C}$ for 30 minutes according to the SIRIM procedure (ISO 3262-1975). The LOI amount of rice husk ash was 2.562 which corresponds to the removal of moisture and the coexisting unburned carbon from samples [26]. The LOI amount of extracted silica powder was $10.64 \%$. Considering the LOI amount of ash which showed the little amount of unburned carbon, most of LOI amounts of the extracted silica powder just corresponded to the removal of moisture from sample.

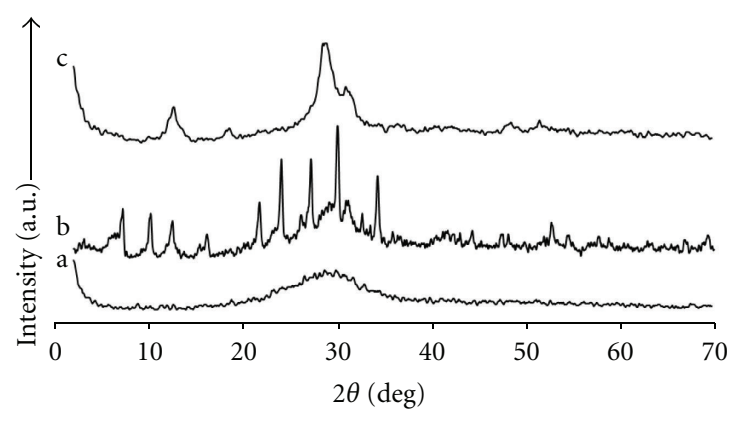

FIGURE 2: The XRD patterns of the final products synthesized using the $\mathrm{Na}_{2} \mathrm{O} / \mathrm{SiO}_{2}$ ratio equal (a) 0.9 , (b) 6 , and (c) 9 .

The composition of the nanozeolite $\mathrm{NaA}$ initial system was calculated based on the XRF analysis results of extracted silica.

3.2. Effect of Alkalinity and $\mathrm{Na}_{2} \mathrm{O} / \mathrm{SiO}_{2}$ Ratio. The effects of $\mathrm{Na}_{2} \mathrm{O} / \mathrm{SiO}_{2}$ ratio on the $\mathrm{NaA}$ nanozeolite was investigated with the compositions of $\mathrm{Na}_{2} \mathrm{O}: 0.55 \mathrm{Al}_{2} \mathrm{O}_{3}: \mathrm{SiO}_{2}: 150 \mathrm{H}_{2} \mathrm{O}$, where $x=0.9,6$, and 9 . The initial composition of ashes and resulted silica are summarized in Table 2 .

The reaction temperature and time are fixed at $25 \pm$ $2^{\circ} \mathrm{C}$ and 3 days, respectively. The crystallization kinetics of any particular zeolite is affected by the alkalinity and composition of the reaction mixture. The $\mathrm{Na}_{2} \mathrm{O} / \mathrm{SiO}_{2}$ ratio had the most pronounced effect on the kinetics of zeolite formation [6]. The $\mathrm{Na}$ cation was added in the form of $\mathrm{NaOH}$, resulting in the concentration of $\mathrm{OH}^{-}$being controlled simultaneously by the concentration of cation [31].

The hydroxide ion affects dissolution and polymerization-depolymerization reactions of silicates and aluminosilicates [32].

The increase of this ratio from 0.9 to 6 leads to the growth of the zeolite crystals on the 3rd day. The $\mathrm{Na}_{2} \mathrm{O} / \mathrm{SiO}_{2}=9$ in the system did not form the zeolite A. Figure 2 shows the XRD patterns of $\mathrm{A} 1, \mathrm{~A} 2$, and $\mathrm{A} 3$. The $\mathrm{Na}_{2} \mathrm{O} / \mathrm{SiO}_{2}=0.9$ is the minimum ratio to dissolve this kind of silica source and to achieve a clear solution with the silica source. The $\mathrm{Na}_{2} \mathrm{O} / \mathrm{SiO}_{2}=0.9$ has resulted in the amorphous phase of the final products (Figure $2(\mathrm{a})$ ).

Peaks at $2 \theta=7.10,10.19$, and 12.49 [33] show that the pure phase of $\mathrm{NaA}$ zeolite was produced with the $\mathrm{Na}_{2} \mathrm{O} / \mathrm{SiO}_{2}=6$ (Figure 2(b)). Al-rich zeolites such as LTA are commonly prepared under basic conditions by using alkali-metal hydroxides as the alkali source. The nature of the inorganic cation is important for the crystallization and the formation of the framework structures of zeolites. Zeolite $\mathrm{NaA}$ could be formed from the aluminosilicate gel system in the presence of sodium-containing species [32].

Alkali-metal cations as the source of hydroxide ions are needed to solubilize silicate and aluminate species and a limited structure-directing role to form cage-like structures [34].

The XRD pattern in Figure 2(c) shows that a zeolite phase other than the NaA type is present in the sample A3 with 
TABLE 2: Effects of $\mathrm{Na}_{2} \mathrm{O} / \mathrm{SiO}_{2}$ ratio on the final products.

\begin{tabular}{lccc}
\hline Run & Molar composition of initial solution & $\mathrm{Na}_{2} \mathrm{O} / \mathrm{SiO}_{2}$ ratio & Product \\
\hline A1 & $0.9 \mathrm{Na}_{2} \mathrm{O}: 0.55 \mathrm{Al}_{2} \mathrm{O}_{3}: 1 \mathrm{SiO}_{2}: 150 \mathrm{H}_{2} \mathrm{O}$ & 0.9 & Amorphous \\
A2 & $6 \mathrm{Na}_{2} \mathrm{O}: 0.55 \mathrm{Al}_{2} \mathrm{O}_{3}: 1 \mathrm{SiO}_{2}: 150 \mathrm{H}_{2} \mathrm{O}$ & 6 & $\mathrm{NaA}$ \\
$\mathrm{A} 3$ & $9 \mathrm{Na}_{2} \mathrm{O}: 0.55 \mathrm{Al}_{2} \mathrm{O}_{3}: 1 \mathrm{SiO}_{2}: 150 \mathrm{H}_{2} \mathrm{O}$ & 9 & $\mathrm{Na}-\mathrm{P} 1$ \\
\hline
\end{tabular}

$\mathrm{Na}_{2} \mathrm{O} / \mathrm{SiO}_{2}=9$. The existence of peaks at $2 \theta=12.46^{\circ}$, $21.67^{\circ}$, and $28.10^{\circ}$ [35], which correspond to the zeolite Na$\mathrm{P} 1$, indicates the presence of zeolite $\mathrm{Na}-\mathrm{P} 1$ instead of zeolite $\mathrm{NaA}$ in $\mathrm{A} 3$.

The formation of zeolite $\mathrm{P}$ might be due to the silica extracted from the rice husk, which is not reactive towards the formation of zeolite $\mathrm{NaA}$. The silicate source is an additional parameter that can influence the particle size of the product [36]. It was found that the zeolite formation is very sensitive to the nature of the reactants, in particular that of the silica source [6]. This factor is important in the nucleation kinetics [36]. The silica source can influence different aspects of the zeolite crystallization, including the kinetics of crystal growth and the properties of the final product $[37,38]$. The use of different silica sources significantly influences the outcome of the synthesis experiments [38]. It has been reported that zeolites synthesized from less reactive rice husk ash silica consist of a mixture of zeolite $\mathrm{Y}$ and $\mathrm{P}$ [39].

To obtain zeolite $\mathrm{A}$ in a reasonable period of time at room temperature, a highly alkaline condition was applied by mixing freshly prepared aluminate and silicate solutions as shown above. A higher alkalinity increases the solubility of the $\mathrm{Si}$ and $\mathrm{Al}$ sources, decreases the polymerization degree of the silicate anions, and accelerates the polymerization of the polysilicate and aluminate anions. Consequently, the increase of alkalinity will shorten the induction and nucleation periods and speed up the crystallization of zeolites [32].

Scanning electron microscopy images were recorded for the extracted silica-synthesized zeolitic samples, some of which are shown in Figure 3. Figure 3(a) shows products in sample A3 of which $\mathrm{P}$ type of zeolite was synthesized. Figure 3(b) shows the SEM images of prepared nanozeolite $\mathrm{NaA}$. Figure 3(b) indicates that the particle size of synthesized nanozeolite $\mathrm{NaA}$ is fine and within a range of 50$120 \mathrm{~nm}$.

3.3. Effect of Crystallization Time. The crystallization time is one of the significant parameters in the synthesis of zeolites. To examine the effect of time, a series of experiments were conducted by changing the crystallization period $(1,2$, and 3 days) with the initial system composition constant. The times of crystallization as well as the resulted products with initial composition: $6 \mathrm{Na}_{2} \mathrm{O}: 0.55 \mathrm{Al}_{2} \mathrm{O}_{3}: 1 \mathrm{SiO}_{2}: 150 \mathrm{H}_{2} \mathrm{O}$ are summarized in Table 3.

The powder X-ray diffraction patterns taken after different hydrothermal crystallization periods, while using the extracted silica as source, maintaining the same (room) temperature and stirrer conditions, are presented in Figure 4. Furthermore, by increasing the reaction time from 1 to 3

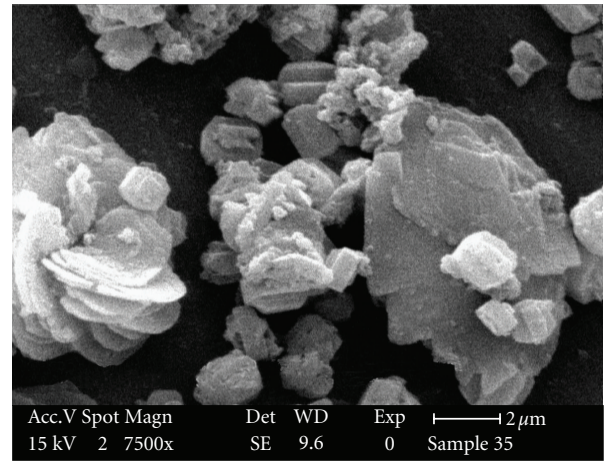

(a)

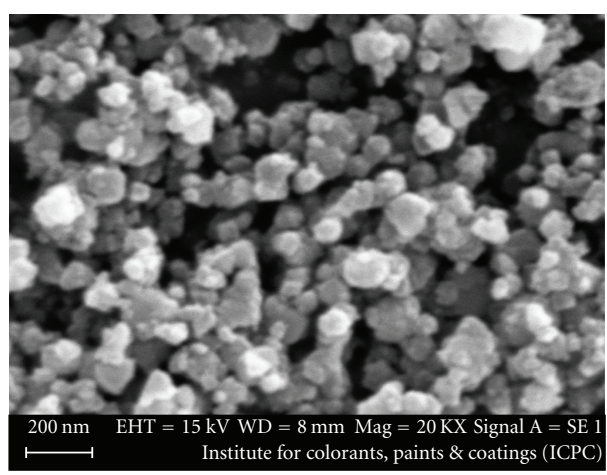

(b)

FIGURE 3: SEM images of of the final products synthesized using the $\mathrm{Na}_{2} \mathrm{O} / \mathrm{SiO}_{2}$ ratio equal (a) 9 and (b) 6 .

TABLE 3: Effects of heating time on the synthesis of $\mathrm{NaA}$ zeolite with initial composition: $6 \mathrm{Na}_{2} \mathrm{O}: 0.55 \mathrm{Al}_{2} \mathrm{O}_{3}: 1 \mathrm{SiO}_{2}: 150 \mathrm{H}_{2} \mathrm{O}$.

\begin{tabular}{lcc}
\hline Run & Heating time $(\mathrm{d})$ & Product \\
\hline A4 & 1 & Amorphous \\
A5 & 2 & Amorphous \\
A2 & 3 & NaA \\
\hline
\end{tabular}

days, the crystallinity of samples increased significantly. It was found that $\mathrm{NaA}$ nanocrystals are formed after heating for 3 days at room temperature (Figure 4(c)).

In general, the crystallinity and crystal size increase with increasing time [3]. In present study, we synthesize zeolite $\mathrm{NaA}$ at room temperature with nanometer size without using any organic template during 3 days. The crystallization at a moderate temperature has a pronounced effect on the ultimate zeolite crystal size [6]. 


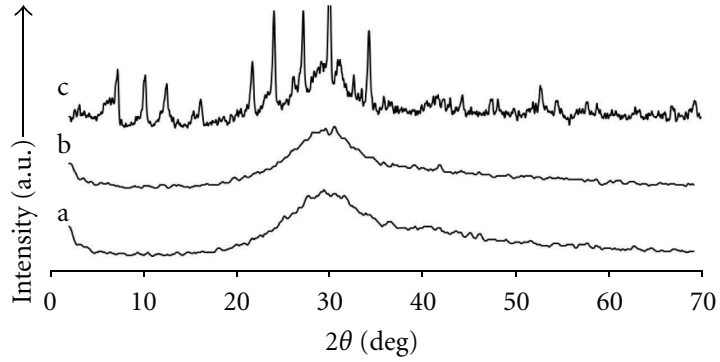

FIgURE 4: The X-ray diffraction patterns of final products after (a) 1 , (b) 2, and (c) 3 day.

The increase in temperature will increase both the nucleation rate and the crystal growth rate, in particular the crystal growth rate over the nucleation rate. Thus, higher growth rates and larger crystals have been obtained at higher temperature [32]. As a rule, lower temperatures lead to smaller particle sizes, however, at the expense of a substantial decrease in the rate of crystallization [6]. Sand et al. [40] obtained LTA-type zeolite after 30 days at room temperature. Valtchev and Bozhilov [41] synthesized FAU type of zeolite containing $100-300 \mathrm{~nm}$ spherical aggregates under room temperature in a template-free system after 3 weeks of synthesis.

As mentioned above, to obtain nanozeolite $\mathrm{NaA}$ in a reasonable period of time at room temperature, a highly alkaline condition was employed. The increase of alkalinity will speed up the crystallization of zeolites. The change of alkalinity also has an effect on the particle size of zeolites. The increase in alkalinity resulted in a decrease of particle size [32].

There are some studies dealing with zeolite synthesis using rice husk ash as an alternative silica source [15-17, 26, 42,43 ]. Although rice husk has been used for zeolite synthesis instead of pure chemical sources in all the above-mentioned studies, in the present study, the result of XRD and SEM analysis confirmed synthesis of zeolite $\mathrm{NaA}$ with extracted silica from rice husk as source without adding any organictemplate and in nanometer size in 3 days, which has not yet been reported.

The synthesis of nanozeolite $\mathrm{NaA}$ at room temperature favored the nucleation process, since the activation energy of crystal growth is generally higher than that of nucleation. This is one key route to synthesize nanozeolites without using any organic additives $[3,6,44]$.

We have used extracted silica from rice husk as an alternative silica source which reduces the costs of synthesis effectively through utilization of cheap raw materials considering low cost of rice husk. Therefore, utilization of this agricultural byproduct for nanozeolite NaA synthesis would result in the conversion of a low-cost raw material into a high-value added product.

Also, the zeolite $\mathrm{NaA}$ synthesized in nanometer size from rice husk without the use of organic template has the advantage of low-cost and other advantages. Most studies on zeolite synthesis have used an organic template [26, 42, 43] which increases the cost of nanozeolite synthesis. Organic templates, for example, tetramethylammonium hydroxide (TMAOH), make $50 \%$ of the production cost and require calcinations which result in the production of $\mathrm{CO}_{2}$ and $\mathrm{NO}_{x}$ pollution problems [45]. In our environmentally friendly process, no expensive organic template was used, and so, the cost of synthesis can be decreased. Moreover, specialized instruments for burning excess TMA after synthesis were avoided which resulted in lower disposal costs.

Approximately one fifth of the ash is obtained on burning rice husk in air [46]. About $95.913 \mathrm{~g}$ of silica was extracted per $100 \mathrm{~g}$ of rice husk ash (Table 1). In our study, $1.26 \mathrm{~g}$ of extracted silica yielded $0.39 \mathrm{~g}$ nanozeolite $\mathrm{NaA}$ approximately. Totally, about $74.22 \mathrm{~kg}$ of nanozeolite $\mathrm{NaA}$ was produced per ton of rice husk, considering low cost of rice husk. Therefore, utilization of this agricultural byproduct for nanozeolite NaA synthesis would result in the conversion of a low-cost raw material into a high-value added product.

\subsection{STEM and SAED Analysis of Synthesized Nanozeo-} lite $\mathrm{NaA}$. The scanning transmission electron microscopy (STEM) images and selected area electron diffraction (SAED) pattern of the synthesized nanozeolite (sample A2) are shown in Figure 5. The STEM image indicates that the products are crystalline aggregates with a diameter of about $150 \mathrm{~nm}$ of NaA nanocrystals (Figure 5(a)). The STEM images confirm that synthesized $\mathrm{NaA}$ zeolite has nanometer particle size ranging from 20 to $120 \mathrm{~nm}$ (Figure 5(b)).

The SAED pattern (Figure 5(c)) from the synthesized nanozeolite showed that the axes of all whiskers are parallel to the [111] direction, indicating the LTA-type structure [47] and is in well agreement with the XRD study. The diffraction rings also demonstrated that the LTA types were crystalline.

3.5. EDX and XRF Analysis of Synthesized Nanozeolite NaA. Typically, zeolite LTA is synthesized with framework $\mathrm{Si} / \mathrm{Al}$ ratio of 1 [33]. By using tetramethylammonium cation $\left(\mathrm{TMA}^{+}\right)$as the SDA, the Si/Al ratio of LTA framework could be increased up to about 3 [32]. The Si/Al and $\mathrm{Na}_{2} \mathrm{O} / \mathrm{SiO}_{2}$ ratios resulting in nanozeolite $\mathrm{NaA}$ after 3 days with $\mathrm{Na}_{2} \mathrm{O} / \mathrm{SiO}_{2}=6$ were determined by EDX technique as 1.49 and 0.18 , respectively. Figure 6 shows the EDX analysis of obtained nanozeolite NaA. The XRF analysis results of synthesized nanozeolite $\mathrm{NaA}$ were LOI : 19.29, $\mathrm{SiO}_{2}: 35.778$, $\mathrm{Al}_{2} \mathrm{O}_{3}: 29.444$, and $\mathrm{Na}_{2} \mathrm{O}: 15.295$ (wt\%). According to the $\mathrm{XRF}$ results, the $\mathrm{Si} / \mathrm{Al}$ and $\mathrm{Na}_{2} \mathrm{O} / \mathrm{SiO}_{2}$ ratios were 1.071 and 0.427 , respectively. Thus, the zeolite $\mathrm{NaA}$ was confirmed by the EDX and XRF techniques.

3.6. Surface Texture of Synthesized Nanozeolite NaA. Figure 7 shows the $\mathrm{N}_{2}$ adsorption/desorption isotherm of the prepared $\mathrm{NaA}$ nanozeolite. The NaA nanocrystals were characterized by using $\mathrm{N}_{2}$ adsorption/desorption measurements to determine their pore volume and surface area. As is known, zeolite $\mathrm{A}$ in its sodium form does not adsorb the $\mathrm{N}_{2}$ molecule. Indeed, the adsorption/desorption isotherm of the product was of type III, typical of nonporous materials. The increase in the volume adsorbed at very low relative 


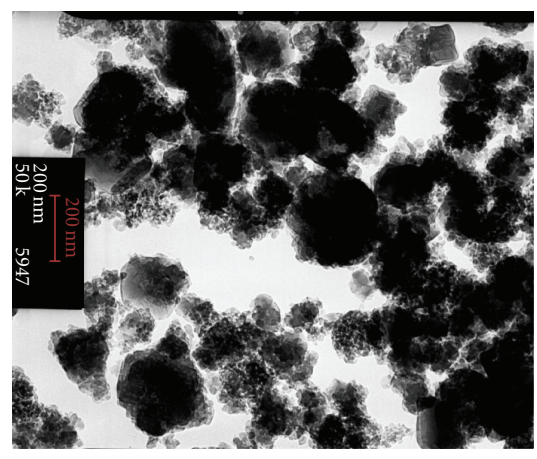

(a)

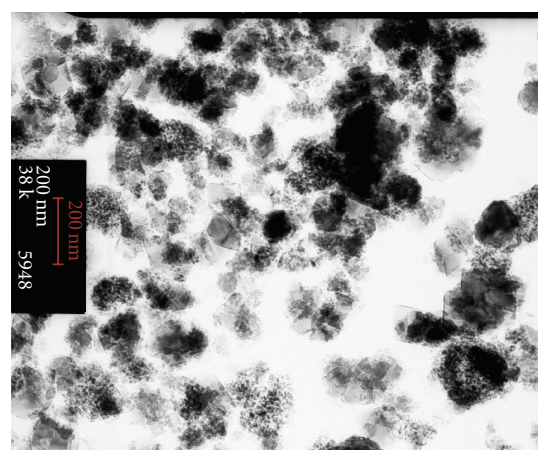

(b)

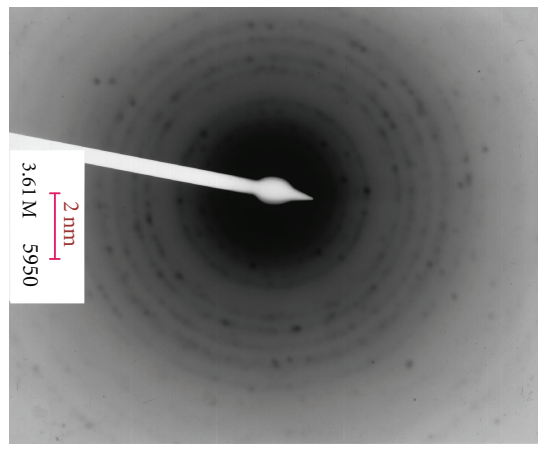

(c)

FIGURE 5: ( $a$ and b) STEM images of nanosized NaA crystals and (b) SAED pattern obtained from the synthesized nanozeolite.

pressures was due to the presence of a small amount of micropores, most probably related to the adsorption of $\mathrm{N}_{2}$ molecules at the pore openings [6]. The specific surface area of this sample was $64.203 \mathrm{~m}^{2} \mathrm{~g}^{-1}$, which suggests nanometersized particles. The large external surface of the resulting $\mathrm{NaA}$ zeolite was $62.520 \mathrm{~m}^{2} \mathrm{~g}^{-1}$, which further supports that $\mathrm{NaA}$ nanocrystals have small crystallite sizes.

In contrast to pure microporous materials, the steep uptake at low relative pressure is not followed by a flat curve. Instead, an inclination of the curve with an increase of the relative pressure and a second uptake at a high relative pressure, indicative of some textural mesoporosity, can be observed. Due to this secondary porosity, the material synthesized at room temperature showed a higher total pore volume compared to that of the reference zeolite A sample [6].

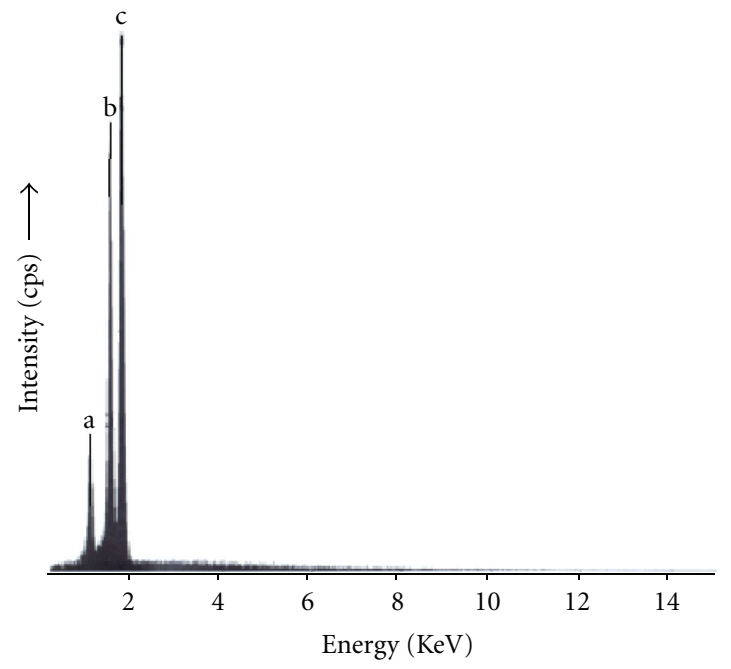

$$
\begin{aligned}
& \mathrm{A}=\mathrm{NaK} \alpha \\
& \mathrm{B}=\mathrm{AlK} \alpha \\
& \mathrm{C}=\mathrm{SiK} \alpha
\end{aligned}
$$

FIgURE 6: The EDX analysis pattern of obtained nanozeolite NaA.

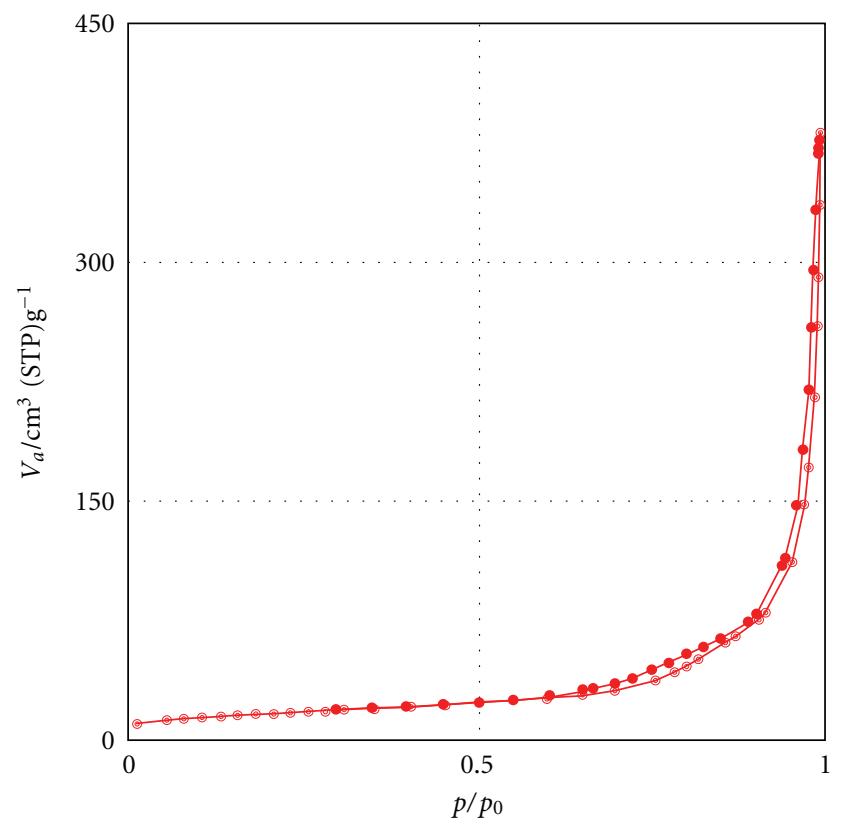

FIgure 7: The $\mathrm{N}_{2}$ adsorption/desorption isotherm of the prepared nanozeolite NaA.

\section{Conclusion}

In this paper, instead of pure chemicals, rice husk which is an agricultural waste was used as silica source for the synthesis of nanozeolite $\mathrm{NaA}$, because silica extracted from rice husk is cheap, less selective, and highly active. Amorphous extracted silica powder was composed of 87.988 $\mathrm{wt} \% \mathrm{SiO}_{2}$. We have successfully synthesized nanometer-sized $\mathrm{NaA}$ nanozeolite with extracted silica at room temperature 
without using any organic additives. Also, the effect of alkalinity and $\mathrm{Na}_{2} \mathrm{O} / \mathrm{SiO}_{2}$ ratio of initial system, as well as time of crystallization, on the properties of the final product was investigated. Zeolite $\mathrm{NaA}$ nanocrystals with crystallite size ranging from $50-120 \mathrm{~nm}$ were obtained from a sodium aluminosilicate solution at room temperature in 3 days under $\mathrm{Na}_{2} \mathrm{O} / \mathrm{SiO}_{2}=6$ conditions. Thus the aims to lower costs and to shorten crystallization time were both found possible through the study.

To the best of our knowledge, this is the first report on the hydrothermal synthesis of zeolite $\mathrm{NaA}$ nanocrystals with rice husk as source of extracted silica, without using any organic additives during the whole crystallization process. Our environmentally friendly process reduces the costs of synthesis effectively through the utilization of cheap raw materials and also by avoiding consumption of expensive chemical sources as template.

\section{Acknowledgments}

This study was supported by a research grant from Tarbiat Modares University (TMU), Iran Nanotechnology Initiative Council, and SPAG Zeolite R \& D Group. The authors wish to thank Mr. F. Farhadi, Mr. M. Sardari, and Mr. I. Sourinejad for their technical assistance during the experiments and Ellen Vuosalo Tavakoli for the final editing of the English text.

\section{References}

[1] D. W. Breck, Zeolite Molecular Sieves, John Wiley \& Sons, London, UK, 1974.

[2] R. M. Barrer, Hydrothermal Chemistry of Zeolites, Academic Press, London, UK, 1982.

[3] B. Z. Zhan, M. A. White, M. Lumsden et al., "Control of particle size and surface properties of crystals of NaX zeolite," Chemistry of Materials, vol. 14, no. 9, pp. 3636-3642, 2002.

[4] S. Mintova, N. H. Olson, V. Valtchev, and T. Bein, "Mechanism of zeolite a nanocrystal growth from colloids at room temperature," Science, vol. 283, no. 5404, pp. 958-960, 1999.

[5] R. W. Tschernich, Zeolites of the World, Geoscience Press Inc., Phoenix, Ariz, USA, 1992.

[6] V. P. Valtchev, L. Tosheva, and K. N. Bozhilov, "Synthesis of zeolite nanocrystals at room temperature," Langmuir, vol. 21, no. 23, pp. 10724-10729, 2005.

[7] G. Zhu, S. Qiu, J. Yu et al., " Synthesis and characterization of high-quality zeolite LTA and FAU single nanocrystals," Chemistry of Materials, vol. 10, pp. 1483-1486, 1998.

[8] R. Ravishankar, C. Kirschhock, B. J. Schoeman et al., "Physicochemical characterization of silicalite-1 nanophase material," Journal of Physical Chemistry B, vol. 102, no. 15, pp. 2633 2639, 1998.

[9] S. Mintova, V. Valtchev, I. Kiricsi, G. Pál-Borbély, J. B. Nagy, and H. G. Karge, Synthesis of Nanosized FAU-Type ZeoliteStudies in Surface Science and Catalysis, Elsevier, Cambridge, Mass, USA, 1999.

[10] C. Madsen and C. J. H. Jacobsen, "Nanosized zeolite crystals - Convenient control of crystal size distribution by confined space synthesis," Chemical Communications, no. 8, pp. 673674, 1999.
[11] M. Xu, M. Cheng, and X. Bao, "Growth of ultrafine zeolite Y crystals on metakaolin microspheres," Chemical Communications, no. 19, pp. 1873-1874, 2000.

[12] H. Wang, Z. Wang, and Y. Yan, "Colloidal suspensions of template-removed zeolite nanocrystals," Chemical Communications, no. 23, pp. 2333-2334, 2000.

[13] Y. Pan, M. Ju, J. Yao, L. Zhang, and N. Xu, "Preparation of uniform nano-sized zeolite A crystals in microstructured reactors using manipulated organic template-free synthesis solutions," Chemical Communications, no. 46, pp. 7233-7235, 2009.

[14] E. Roland, H. G. Karge, and J. Weitkamp, "Hindustrial production of zeolites," Studies in Surface Science and Catalysis, vol. 46, pp. 645-659, 1989.

[15] H. Nur, "Direct synthesis of NaA zeolite from rice husk and carbonaceous rice husk ash," Indonesian Journal of Agricultural Sciences, vol. 1, pp. 40-45, 2001.

[16] D. Prasetyoko, Z. Ramli, S. Endud, H. Hamdan, and B. Sulikowski, "Conversion of rice husk ash to zeolite beta," Waste Management, vol. 26, no. 10, pp. 1173-1179, 2006.

[17] A. V. Rawtani, M. S. Rao, and K. V. G. K. Gokhale, "Synthesis of ZSM-5 zeolite using silica from rice husk ash," Industrial and Engineering Chemistry Research, vol. 28, no. 9, pp. 1411$1414,1989$.

[18] Z. Ramli, Rhenium-impregnated zeolites: synthesis, characterization and modification ascatalysts in the metathesis of alkanes, Ph.D. thesis, Universiti Teknologi Malaysia, 1995.

[19] M. Y. A. Fuad, Z. Ismail, Z. A. M. Ishak, and A. K. M. Omar, "Application of rice husk ash as fillers in polypropylene: effect of titanate, zirconate and silane coupling agents," European Polymer Journal, vol. 31, no. 9, pp. 885-893, 1995.

[20] M. Bhagiyalakshmi, R. Anuradha, M. Palanichamy, and H. T. Jang, "Dexterous template-free synthesis of ferrisilicate with MFI morphology using rice husk ash," Journal of NonCrystalline Solids, vol. 356, no. 23-24, pp. 1204-1209, 2010.

[21] A. K. Dalai, M. S. Rao, and K. V. G. K. Gokhale, "Synthesis of $\mathrm{NaX}$ zeolite using silica from rice husk ash," Industrial and Engineering Chemistry Product Research and Development, vol. 24, no. 3, pp. 465-468, 1985.

[22] U. Kalapathy, A. Proctor, and J. Shultz, "An improved method for production of silica from rice hull ash," Bioresource Technology, vol. 85, no. 3, pp. 285-289, 2002.

[23] W. Fan, K. Morozumi, R. Kimura, T. Yokoi, and T. Okubo, "Synthesis of nanometer-sized sodalite without adding organic additives," Langmuir, vol. 24, no. 13, pp. 6952-6958, 2008.

[24] X. Shuangning, L. Zhihe, L. Baoming, Y. Weiming, and B. Xueyuan, "Devolatilization characteristics of biomass at flash heating rate," Fuel, vol. 85, no. 5-6, pp. 664-670, 2006.

[25] R. V. Krishnarao, J. Subrahmanyam, and T. Jagadish Kumar, "Studies on the formation of black particles in rice husk silica ash," Journal of the European Ceramic Society, vol. 21, no. 1, pp. 99-104, 2001.

[26] K. Kordatos, S. Gavela, A. Ntziouni, K. N. Pistiolas, A. Kyritsi, and V. Kasselouri-Rigopoulou, "Synthesis of highly siliceous ZSM-5 zeolite using silica from rice husk ash," Microporous and Mesoporous Materials, vol. 115, no. 1-2, pp. 189-196, 2008.

[27] J. Chisholm, "Comparison of quartz standards for X-ray diffraction analysis: HSE A9950 (Sikron F600) and NIST SRM 1878," Annals of Occupational Hygiene, vol. 49, no. 4, pp. 351358, 2005.

[28] H. Hamdan, M. N. M. Muhid, S. Endud, E. Listiorini, and Z. Ramli, "Si MAS NMR, XRD and FESEM studies of rice husk 
silica for the synthesis of zeolites," Journal of Non-Crystalline Solids, vol. 211, no. 1-2, pp. 126-131, 1997.

[29] U. Kalapathy, A. Proctor, and J. Shultz, "A simple method for production of pure silica from rice hull ash," Bioresource Technology, vol. 73, no. 3, pp. 257-262, 2000.

[30] J. Payá, J. Monzó, M. V. Borrachero, A. Mellado, and L. M. Ordoñez, "Determination of amorphous silica in rice husk ash by a rapid analytical method," Cement and Concrete Research, vol. 31, no. 2, pp. 227-231, 2001.

[31] E. M. Flanigen, B. M. Lok, R. L. Patton et al., "Aluminophosphate molecular sieves and the periodic table," Studies in Surface Science and Catalysis, vol. 28, pp. 103-112, 1986.

[32] J. Yu, C. Jirí, S. Ferdi et al., "Chapter 3 Synthesis of zeolites," Studies in Surface Science and Catalysis, vol. 168, pp. 39-103, 2007.

[33] M. M. J. Treacy and J. B. Higgins, Linde Type A, Hydrated Collection of Simulated XRD Powder Patterns for Zeolites, Elsevier Science B.V., Amsterdam, The Netherlands, 5th edition, 2007.

[34] E. J. P. Feijen, J. A. Martens, P. A. Jacobs et al., "Zeolites and their mechanism of synthesis," Studies in Surface Science and Catalysis, vol. 84, pp. 3-21, 1994.

[35] M. M. J. Treacy and J. B. Higgins, Collection of Simulated XRD Powder Patterns for Zeolites, Stucture Commision of the International Zeolite Association, 2001.

[36] F. Kleitz, F. Marlow, G. D. Stucky, and F. Schüth, "Mesoporous silica fibers: synthesis, internal structure, and growth kinetics," Chemistry of Materials, vol. 13, no. 10, pp. 3587-3595, 2001.

[37] K. E. Hamilton, E. N. Coker, A. Sacco, A. G. Dixon, and R. W. Thompson, "The effects of the silica source on the crystallization of zeolite NaX," Zeolites, vol. 13, no. 8, pp. 645$653,1993$.

[38] J. C. Jansen, H. V. Bekkum, E. M. Flanigen, P. A. Jacobs, and J. C. Jansen, "Chapter 5A The preparation of oxide molecular sieves A. Synthesis of zeolites," Studies in Surface Science and Catalysis, vol. 137, pp. 175-227, 2001.

[39] Z. Ramli, E. Listiorini, and H. Hamdan, "Optimization and reactivity study of silica in the synthesis of zeolites from rice husk," Journal Teknologi, vol. 25, pp. 27-35, 1996.

[40] L. B. Sand, A. Sacco, R. W. Thompson, and A. G. Dixon, "Large zeolite crystals: their potential growth in space," Zeolites, vol. 7, no. 5, pp. 387-392, 1987.

[41] V. P. Valtchev and K. N. Bozhilov, "Transmission electron microscopy study of the formation of FAU-type zeolite at room temperature," Journal of Physical Chemistry B, vol. 108, no. 40, pp. 15587-15598, 2004.

[42] S. Loiha, S. Prayoonpokarach, P. Songsiriritthigun, and J. Wittayakun, "Synthesis of zeolite beta with pretreated rice husk silica and its transformation to ZSM-12," Materials Chemistry and Physics, vol. 115, no. 2-3, pp. 637-640, 2009.

[43] M. M. Mohamed, F. I. Zidan, and M. Thabet, "Synthesis of ZSM-5 zeolite from rice husk ash: characterization and implications for photocatalytic degradation catalysts," Microporous and Mesoporous Materials, vol. 108, no. 1-3, pp. 193-203, 2008.

[44] M. Smaihi, O. Barida, and V. Valtchev, "Investigation of the crystallization stages of LTA-type zeolite by complementary characterization techniques," European Journal of Inorganic Chemistry, no. 24, pp. 4370-4377, 2003.

[45] R. K. Vempati, R. Borade, R. S. Hegde, and S. Komarneni, "Template free ZSM-5 from siliceous rice hull ash with varying C contents," Microporous and Mesoporous Materials, vol. 93, no. 1-3, pp. 134-140, 2006.
[46] T. H. Liou, "Preparation and characterization of nano-structured silica from rice husk," Materials Science and Engineering A, vol. 364, no. 1-2, pp. 313-323, 2004.

[47] V. P. Valtchev and K. N. Bozhilov, "Evidences for zeolite nucleation at the solid-liquid interface of gel cavities," Journal of the American Chemical Society, vol. 127, no. 46, pp. 1617116177, 2005. 

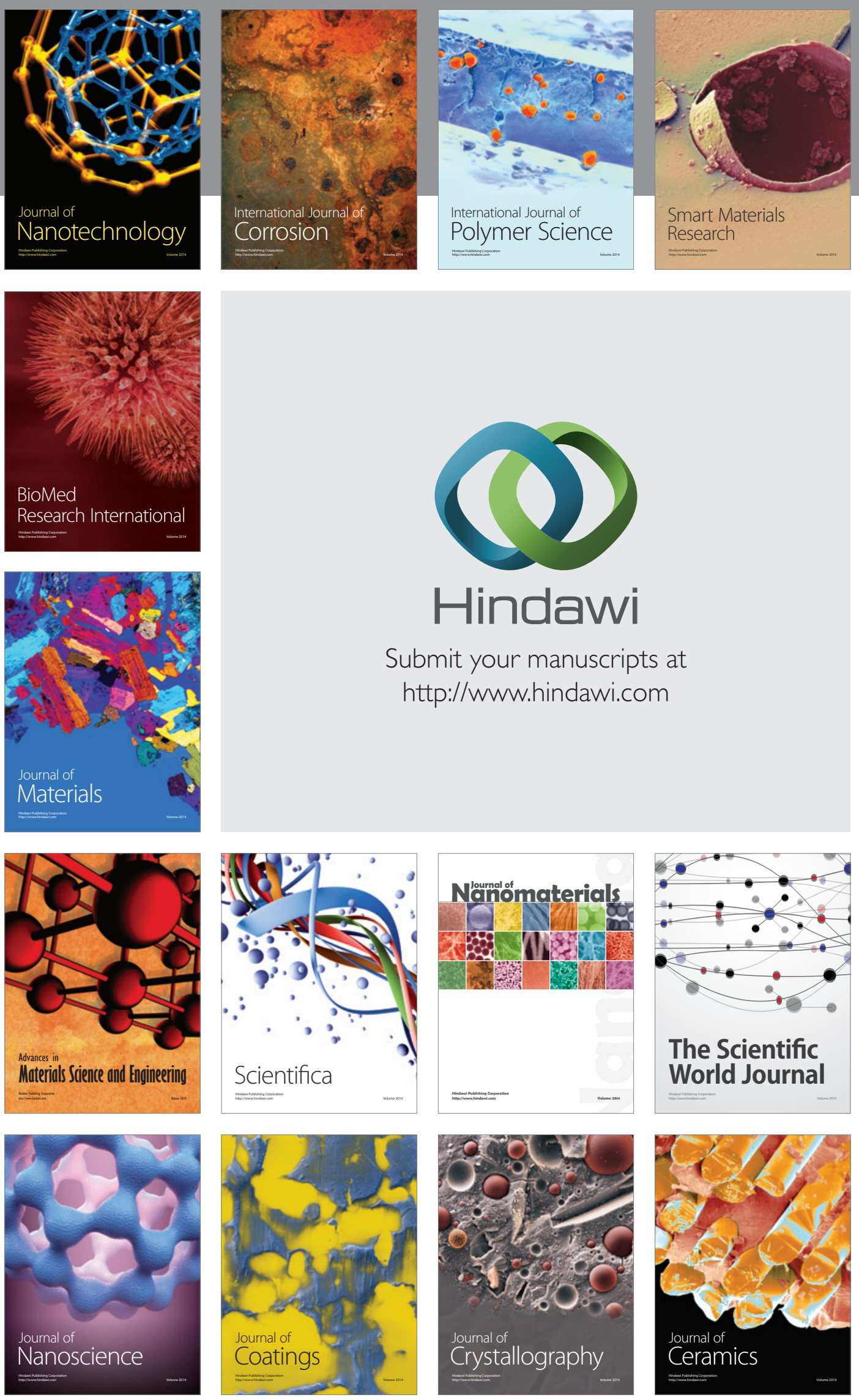

The Scientific World Journal

Submit your manuscripts at

http://www.hindawi.com

\section{World Journal}

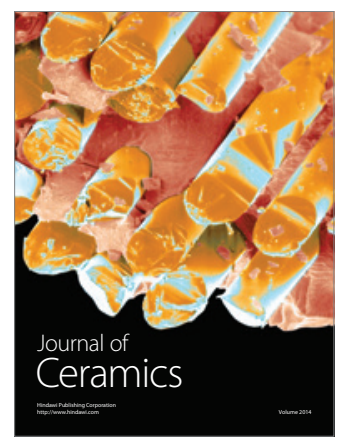

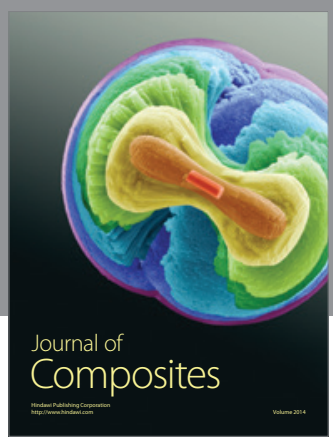
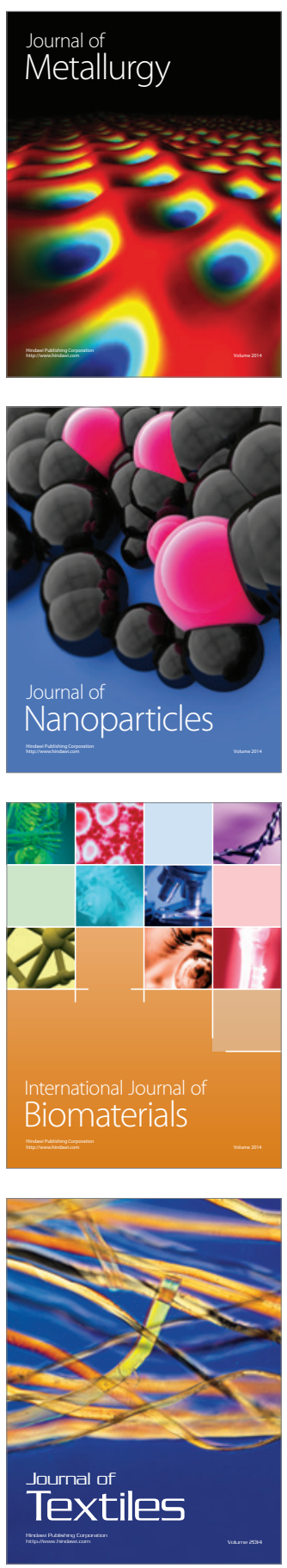